\title{
A Note on the Progressivity of Optimal Public Expenditures
}

\section{Citation}

Green, Jerry R. and Eytan Sheshinski. 1975. A note on the progressivity of optimal public expenditures. Quarterly Journal of Economics 89, no. 1: 138-144.

\section{Published Version}

http://dx.doi.org/10.2307/1881715

\section{Permanent link}

http://nrs.harvard.edu/urn-3:HUL.InstRepos:3203641

\section{Terms of Use}

This article was downloaded from Harvard University's DASH repository, and is made available under the terms and conditions applicable to Other Posted Material, as set forth at http:// nrs.harvard.edu/urn-3:HUL.InstRepos:dash.current.terms-of-use\#LAA

\section{Share Your Story}

The Harvard community has made this article openly available.

Please share how this access benefits you. Submit a story.

Accessibility 


\title{
A NOTE ON THE PROGRESSIVITY OF OPTIMAL PUBLIC EXPENDITURES *
}

\author{
JERRY R. Gikeen \\ EYTAX SHESHINSKI
}

I. Introduction, 138.-- II. Outline of Arow's model and results, 138. - III. Public goods, 139.-- 1V. Fxpenditures ar profuced fonmolitirs, 140.-V. Fxamples, 142....VI Canclusion, 144.

\section{INTRODVCTION}

Professor Arrow has reeently used a utilitarian model to study the optimal distribution of publie expenditure across a population whose members differ in some respect. Let us eall this characteristic "ability." A plausible case is made for the principle that expenditures should be higher for people with low ability, but not so high as to overeome completely the inherent differences -- higher ability leads to ligher utility at the social optimum. This situation is called input-progressive, but output-regressive.

In the field of education, however, it is clear that input regressivity - allocating more resources to the more able - is the current practice. In this note we study the cases in which some of the output of the educational process is in the form of public goods and in which expenditures themselves are produced commodities. It is shown that either of these possibilitics weakens the case for input progressivity. In Arrow's model goods were private, and the level of expenditure was exogenous.

Through several examples we then discuss the dependence of the degree of progressivity on the level of the budget for public expenditures and on the effieieney of production.

\section{Outline of Arrow's Model and Results}

The model considers a population of individuals with ability $x$ varying among them. Let the density of individuals of type $x$ in the population be $n(x)$. The problem is to distribute expenditures

* This work was supported by National Science Foundation Grant GS2874-A1 th the Institute for Mathematical Studies in the Social sciences at Stanford University and by National Science Foundation Grant CrS-31688 at Harvard University. We would like to thank Kenneth Arrow and Robert Wilson for helpful comments.

1. K. J. Arrow, "A Utilitarian Approseh to the Concept of Equality in Public Expenditures," this Journal, LXXXV (Aug. 1971), 409-15. 
$y$ aeross individuals such that the sum of utilities is maximized. Etility depends on ahility and expenditures: $u=u(x, y)$.

Formally, we must choose a function $y(x)$ to maximize

$$
f u(x, y(x) \ln (x) d x
$$

subject to the constraint on total expenditures,

$$
\int y(x) n(x) d x \leq M \text {. }
$$

Arrow shows that the optimal policy can be characterized by the differential exuation,

$$
\frac{d y}{d x}=\frac{-u_{x y}}{u_{y y}}
$$

Sinee $u_{y y}<0$ is needed to insure the seconl-order eonditions, we have the result that input progressivity $\frac{d y}{d x}<0$ holds if $u_{x y}<0$. This is equivalent to the fact that higher ability individuals benefit (in utility) los trom an extra dollar of expenditures. In the case in which utility depends on an objectively measurable output $z(x, y(x))$ only (and not explicitly on $x)$. Arrow shows that the optimal poliey is more progressive as $u$ is more concave, relative to the concavity of $z$. A particularly neat form of this result is obtained for the ease in whieh $z$ can be written implieitly as

$$
H(x)=F(x)+G(y)
$$

in which casc the nptimal policy is input-regressive (progressive) if $\left(\frac{H^{\prime}}{u^{\prime}}\right)$ is incrasing (decrasing) in $z^{\prime}$. Thus, if $\mathrm{u}$ is very concave, indicating a sorial preference for equity of distribution in contrast to efficicney of production, then input progressivity should be the rule.

\section{Prulic Goons}

We consuler the case of an objectively measurable output $z(x, y)$ for ach individual. The utility function, however has three arguments, the third being the aggregate amount of the objectively measurable output in the economy.

Define this aggregate as

$$
Z[y(\cdot)]=\int z(x, y(x)) n(x) d x .
$$

We write $u=u(x, y, Z)$ and denote partial differentiation of $u$ by subscrijts 1,2 , and 3 for $x, y$, and $Z$, respectively.

At an optimum the marginal social value of one dollar of expenditures on any individual is equal to that on any other individual. Thus, 


$$
u_{2}(x, y(x), Z[y])+z_{y}(x, y(x)) \int u_{3}(\xi, y(\xi), Z[y]) n(\xi) d \xi
$$

is constant over $x$. Hence, we obtain

where

$$
\frac{d y(x)}{d x}=\frac{-u_{12}+I z_{x y}}{u_{22}+I z_{y y}}
$$

$$
I=\int u_{3}(\xi, y(\xi), Z[y]) n(\xi) d \xi,
$$

a quantity that is positive whenever aggregate output is a social good.

The denominator of the expression $\left(^{*}\right)$ is negative by the second-order conditions. Thus, we shall tend to have input progressivity if $u_{12}<0$ and $u_{3}$ is small, and input regressivity if $u_{3}$ is large or $z_{x y}$ is large. That is, as one might expect, that as the positive externalities from having a highly productive population in the aggregate become important, public expenditures should be shifted to those individuals whose ability enables them to use it more efficiently. Similarly, as ability and expenditure become more complementary, greater advantage should be taken of this fact by increasing the regressivity of the policy.

To find the actual optimal policy, one solves the differential equation (*) using the budget equation,

$$
\int y(x) n(x) d x=M \text {, }
$$

as an initial condition.

\section{Expenditures as Produced Commodities}

In the above model the allocation of expenditures to one person affects someone else through a pure public good. The discussion can alternatively be recast in terms of an appropriable output that can be reallocated either for direct consumption or for use as an input. One situation in which this occurs naturally is that in which some of the output of a sector is also produced by that sector. Thus raising the level of inputs results in some saving, since outputs available also increase. Education (which produces teachers, in part) is an example of such a sector.

The model we construct has the sector in question producing an objectively measurable net output, or surplus, Z. Individuals' utilities depend on the expenditures allocated to them $y(x)$ and on their share of the surplus $w(x)$. Both $y(x)$ and $w(x)$ are objects of choice, the constraint being that aggregate surplus distributed be at most equal to aggregate production, and given the total expenditures on inputs. Formally, the problem is 


$$
\begin{array}{ll}
\text { maximize } & \int u(w(x), y(x)) n(x) d x \\
\text { subject to } & \int w(x) n(x) d x \leqslant \int z(x, y(x)) n(x) d x \\
\text { and } & \int y(x) n(x) d x \leqslant M .
\end{array}
$$

This leads to the first-order conditions,

and

$$
u_{w}=q
$$

$$
u_{y}=p-q z_{y}
$$

where $q$ and $p$ are Lagrange multipliers. Upon differentiating these conditions, we find that the optimal policy can be characterized by

$$
\left(\left(\frac{u_{y v} u_{w w}-u_{y w}^{2}}{u_{w w}}\right)+q z_{y y}\right) \frac{d y}{d x}=-q z_{x y}
$$

and

$$
\frac{d w}{d x}=-\left(\frac{u_{y w}}{u_{w w}}\right) \frac{d y}{d x} .
$$

Hence, since the coefficient of $\frac{d y}{d x}$ in the first condition is negative by the second-order conditions and the positivity ${ }^{2}$ of $q$, the optimal input policy is progressive (regressive) if ability and direct expenditure are substitutes (complements) in production.

From the second condition it is seen that, if $u_{y w}<0$, then $\frac{d w}{d x}$ has the opposite sign of $\frac{d y}{d x}$, i.e., the optimal surplus distribution policy is progressive (regressive) when the optimal input policy is regressive (progressive). If $u_{y w}>0$, then $\frac{d w}{d x}$ has the same sign as $\frac{d y}{d x}$.

If direct expenditure and surplus distribution are both regressive (progressive), then the optimal output policy is also regressive (progressive). If direct expenditure is regressive but surplus distribution is progressive, output progressivity can go in either direction, depending on the utility function.

Appropriability of output could be restricted solely to input use with the same conclusions. This problem has the form, that

2. Multiplying the above condition by $y n(x) d x$ and integrating, we find

$$
\int u_{y} y n(x) d x=q \int\left(z-z_{y} y\right) u(x) d x .
$$

On the right-hand side each of the terms $z-z_{y} y$ is positive by the concavity of $z$. Since the left-hand side is positive, we see that $q>0$. Note that the above solution yields a direct interpretation of $q$ as the shadow price of expenditures. 
maximize $\int u(x, y(x)) n(x) d x$

subject to $\int y(x) n(x) d x \leqslant \int z(x, y(x)) n(x) d x$.

From the first-order condition one obtains

$$
\left(u_{y y}+q z_{y y}\right) \frac{d y}{d x}=-\left(u_{x y}+q z_{x y}\right) .
$$

Since the term in parentheses on the left-hand side is negative, the sign of $\frac{d y}{d x}$ depends, as previously, on the signs of $u_{x y}$ and $z_{x y}$ with the appropriate interpretation.

The similarity of the results in this and in the previous section is not surprising, since an appropriable output with fixed allocation rules can be described as a pure public good.

\section{EXAMPLES}

The previous sections have shown that there may be some case for input regressivity when the expenditure produces public goods or when expenditures are constrained by aggregate output that in turn depends on ability. Here we present some comparative static calculations that further strengthen the case for input regressivity. In particular, we study the response of the optimal policy to changes in the budget constraint and the technological productivity of expenditures. In all instances, higher levels of expenditure or higher productivity lead to more regressive policies.

Example 1: Public Goods - Changes in Budget. In the framework of Section III let us, for simplicity, specialize to the case in which utility depends only on the output of the public good $Z$ and in which production is Cobb-Douglas, $z(x, y)=x^{a} y^{1-a}$. One can show that

$$
\frac{d\left(\frac{d y}{d x}\right)}{d M}=\frac{d y}{d M} I^{2} z_{x y} z_{y \nu}\left(\frac{z_{y y y}}{z_{y y}}-\frac{z_{x y y}}{z_{x y}}\right) .
$$

Since $z_{\nu}(x, y(x, M))$ is a constant over $x$, say, $q(M)$, we have that

$$
z_{y y} \frac{d y}{d M}=\frac{d q}{d M} .
$$

Integrating over $x$, we obtain

$$
\int \frac{d y}{d M} n(x) d x=\frac{d q}{d M} \int \frac{1}{z_{y y}} n(x) d x,
$$

and the left-hand side is 1 , by the budget constraint. Since $z_{y y}<0$, 
we have $\frac{d q}{d M}<0$. Hence, since $q$ is independent of $x, \frac{d y}{d M}>0$ for all $x$.

By the first equation of this section the optimal policy becomes more input-regressive as expenditures increase if the term in parentheses is negative. That this is the case for Cobb-Douglas production functions can be verified directly.

Example 2: Private Goods (Arrow's case of objectively measurable outputs) - Change in Budget. For contrast, we consider the case in which $u=u(z(x, y))$, which may be thought of as the pure private goods case as opposed to the pure public goods case treated above. If $z(x, y)=x^{a} y^{1-a}$, it can be shown that

$$
\frac{d\left(\frac{d y}{d x}\right)}{d M}
$$

is proportional to

$$
\left(u^{\prime} u^{\prime \prime \prime}-2 u^{\prime \prime}\right)(1-a) z^{2}+\left(u^{\prime}+z u^{\prime \prime}\right)\left(a u^{\prime} y^{1-a}\right) .
$$

The term $\left(u^{\prime} u^{\prime \prime \prime}-2 u^{\prime \prime}\right)$ is positive (negative) if the coefficient of absolute risk aversion is decreasing (increasing). The term $\left(u^{\prime}+z u^{\prime \prime}\right)$ has the same sign as one minus the coefficient of relative risk aversion. Since decreasing absolute risk aversion is thought to be the intuitively ${ }^{3}$ appealing case, there is a bias in the direction of increasing input regressivity, even in Arrow's model, as the budget is expanded.

Example 3: Public Goods - Changes in Productivity. Suppose that the productivity of expenditures is parameterized by $\lambda$ according to $z=x^{a}(\lambda y)^{1-a}$ and that $U=U(Z)$. One can show that

$$
\frac{d\left(\frac{d y}{d x}\right)}{d \lambda}
$$

is proportional to

$$
z_{x y} z_{y y \lambda}-z_{y y} z_{x y \lambda}
$$

3. See K. J. Arrow, Aspects of the Theory of Risk Bearing (Helsinki : Academic Bookstore, 1965). Arguments for using the von-Neumann-Morgenstern utility function in utilitarian social choice theory can be found in W. $\mathrm{S}$. Vickrey, "Utility, Strategy, and Social Decision Rules," this Journal, LXXIV (Nov. 1960), 507-35; and J. C. Harsanyi, "Cardinal 'Welfare, Individualistic Ethics, and Interpersonal Comparisons of Utility," Journal of Political Economy, LXIII (Aug. 1955), 309-21. (Both works are reprinted in Readings in Welfare Economics, K. J. Arrow and T. Scitovsky, eds. (Homewood, Ill.: R. D. Irwin, 1969.) 
which is positive in the Cobb-Douglas case. Thus, increasing input regressivity should be practiced as the productivity of public expenditures increases (in this particular parametric form).

Example 4: Produced Expenditures - Changes in Budget. In the framework of Section IV assume that the budget is partly produced and in part given exogenously. The budget constraint thus takes the form

$$
\int y(x) n(x) d x=M+\int z(x, y) n(x) d x
$$

where $M$ is the exogenously given level of resources minus the aggregate surplus to be distributed. For the additive utility case, $u(w y)=f(w) g(y)$, it is easily shown that, for the optimal policy $\frac{d y}{d M}$ is positive for all $x$. One can also show that, for the CobbDouglas production function,

$$
\frac{d\left(\frac{d y}{d x}\right)}{d M}
$$

is positive for all $x$.

\section{Conclusion}

It is clear that the progressivity of public expenditures cannot be determined by such simple utilitarian criteria. However, our analysis (as well as Arrow's) brings out some considerations that should enter into practical decision making. We have shown that there may be economic forces working towards regressivity as well as towards progressivity of expenditures.

HaRvard University

The Hebrew University of Jerusalem 
Copyright of Quarterly Journal of Economics is the property of MIT Press. The copyright in an individual article may be maintained by the author in certain cases. Content may not be copied or emailed to multiple sites or posted to a listserv without the copyright holder's express written permission. However, users may print, download, or email articles for individual use. 